\title{
Simulating Impacts of Extreme Weather Events on Urban Transport Infrastructure in the UK
}

\author{
Alistair Ford ${ }^{1}$, Katie Jenkins ${ }^{2}$, Richard Dawson', Maria Pregnolato', Stuart Barr ${ }^{1}$ and Jim Hall ${ }^{2}$ \\ ${ }^{1}$ School of Civil Engineering and Geosciences, Newcastle University, UK \\ ${ }^{2}$ Environmental Change Institute, University of Oxford, UK
}

\begin{abstract}
Urban areas face many risks from future climate change and their infrastructure will be placed under more pressure due to changes in climate extremes. Using the Tyndall Centre Urban Integrated Assessment Framework, this paper describes a methodology used to assess the impacts of future climate extremes on transport infrastructure in London. Utilising high-resolution projections for future climate in the UK, alongside stochastic weather generators for downscaling, urban temperature and flooding models are used to provide information on the likelihood of future extremes. These are then coupled with spatial network models of urban transport infrastructure and, using thresholds to define the point at which systems cease to function normally, disruption to the networks can be simulated. Results are shown for both extreme heat and urban surface water flooding events and the impacts on the travelling population, in terms of both disruption time and monetary cost.
\end{abstract}

Keywords: Infrastructure, Extreme Weather, Urban Flooding, Transportation

\section{INTRODUCTION}

The IPCC $5^{\text {th }}$ Assessment Working Group 2 (IPCC, 2014) report on climate impacts highlights the risks faced in urban areas by future climate change, but also that the complex nature of urban areas and their interconnected systems offer an ideal opportunity for climate change adaptation leadership. In particular, infrastructure in cities will be placed under more pressure in the future due to the changes in climate extremes (e.g. rainfall and temperature) and the concurrent increase in demand from population growth and urbanisation (Hallegatte and Corfee-Morlot, 2011) 2. In order to understand where these future pressures may be spatially-concentrated, it is important to study urban infrastructure in the context of both climate change and socio-economic change. To this end, the Tyndall Centre's Urban Integrated Assessment Framework (UIAF) was developed (Hall et al, 2010) ${ }^{3}$ to allow the assessment of the urban impacts of climate change coincident with other changes which may be seen in cities.

\footnotetext{
$1 \quad$ IPCC (2014). Climate Change 2014: Impacts, Adaptation, and Vulnerability. Part A: Global and Sectoral Aspects. Contribution of Working Group II to the Fifth Assessment Report of the Intergovernmental Panel on Climate Change, [Field, C.B., V.R. Barros, D.J. Dokken, K.J. Mach, M.D. Mastrandrea, T.E. Bilir, M. Chatterjee, K.L. Ebi, Y.O. Estrada, R.C. Genova, B. Girma, E.S. Kissel, A.N. Levy, S. MacCracken, P.R. Mastrandrea, and L.L. White (eds.)]. Cambridge University Press, Cambridge, United Kingdom and New York, USA, Draft Chapter 8.

2 Hallegatte, S. \& Corfee-Morlot, J. 2011. Understanding climate change impacts, vulnerability and adaptation at city scale: an introduction. Climatic Change, 104, 1-12.

3 Hall JW, Dawson RJ, Barr SL, Batty M, Bristow AL, Carney S, Dagoumas A, Ford A, Tight MR, Walsh CL, Watters H, Zanni AM, (2010). City-scale integrated assessment of climate impacts, adaptation and mitigation. In: Bose, R.K, ed. Energy Efficient Cities: Assessment Tools and Benchmarking Practices. Washington, DC, USA: World Bank, pp.43-64.
} 
The work presented in this paper highlights a rapid assessment methodology using the UIAF for understanding potential future impacts on the users of urban transport networks from extreme weather events. This begins with climate downscaling using the UKCP Weather Generator and, in the case of extreme rainfall, simulation of surface water flooding using the CityCat model (Glenis et al, 2013) ${ }^{4}$. The spatial footprints of resulting climate hazards are then overlaid on the urban transport networks (for both public and private travel) and thresholds applied to understand where impacts will be felt. These impacts can then be assessed in terms of increased travel time for the users of the transport infrastructure and the total cost of disruption calculated. This methodology is demonstrated in this paper for both extreme heat and extreme rainfall events, on public transport and road networks in the UK.

\section{METHODOLOGY}

This study employs the Tyndall Centre UIAF, which couples models of climate, population, transport, and land-use to allow a system-scale analysis of the inter-relationships between climate impacts, transport networks, urban residents, and the urban economy (Hall et al., 2010) ${ }^{3}$. In order to provide information on the likelihood of extreme weather events, impacts, and implications for adaptation policies, which are sometimes lacking in scenario-based city-scale climate change impact assessments, the UIAF has been extended to enable a probabilistic risk-based approach (Jenkins et al, 2012) ${ }^{5}$. This approach will be outlined for heat impacts on transport networks, whilst a more simple deterministic approach will be described for the impacts of surface water flooding.

Since the spatial and temporal resolution of climate model outputs (e.g. $25 \mathrm{~km}^{2}$ for the UK Climate Projections (UKCP09) 6 ) is often too coarse for studies of climate change impacts, downscaling techniques are often employed to produce outputs at a more suitable scale. An Urban Weather Generator (UWG) has thus been produced to supplement the UKCP09 outputs, providing hourly time series of weather variables, such as rainfall or maximum temperature) for various future climate scenarios at $5 \mathrm{~km}$ resolution. The UWG employs a stochastic rainfall model to simulate time series of future rainfall, and thus other weather variables dependent on this initial output. Change factors can be employed to adjust the statistical measures used by the UWG based on probabilistic projections from UKCP09 (Jones et al., 2009)7. Recent advances in the UWG give an improved reproduction of extreme temperatures, spatial correlations in weather (Kilsby et al., 2011) ${ }^{8}$, and urban heat island effects (McCarthy et al., 2012) ${ }^{9}$.

The outputs from the UWG (e.g. hourly data of weather variables at $5 \mathrm{~km}$ resolution) are used to assess the spatial and temporal variation of hazards in the urban area. In order to simplify analysis, a thresholding approach is applied where lower-order impacts are assessed when the climate inputs exceed a certain level of severity. For extreme heat events, temperature thresholds are defined above which it is expected disruption will begin to be felt on transport networks. For extreme rainfall events, a further intermediate step is needed to translate heavy rain into flood extents using CityCat, the thresholding being applied to the resultant depths of water.

\section{HEAT IMPACTS}

Dobney et al., $(2010,2009)^{10,11}$ showed that disruption to the railway network in London and the South East can

4 Glenis V, McGough AS, Kutija V, Kilsby C, Woodman S. (2013) Flood modelling for cities using Cloud computing. Journal of Cloud Computing: Advances, Systems and Applications, 2(1), 7.

5 Jenkins, K., Glenis, V., Ford, A., Hall, J.(2012) "A Probabilistic Risk-Based Approach to Addressing Impacts of Climate Change on Cities: The Tyndall Centre's Urban Integrated Assessment Framework". UGEC Viewpoints, Connecting Past and Present Lessons in Urbanization and the Environment (8).

6 UKCP09 (n.d.) UKCP09 25 km grid, last updated Tuesday, 17 July 2012, http://ukclimateprojections.metoffice.gov.uk/23233

7 Jones, P. D., Kilsby, C. G., Harpham, C., Glenis, V. \& Burton, A. (2009). UK Climate Projections science report: Projections of future daily climate for the UK from the Weather Generator. University of Newcastle, UK.

8 Kilsby, C., Jones, P., Harpham, C., Glenis, V. \& Burton, A. (2011). Spatial Urban weather Generator for Future Climates. ARCADIA Task 3 Report. Avaliable at: http://www.arcc-cn.org.uk/wp-content/pdfs/ARCADIA-7.pdf.

9 McCarthy, M. P., Harpham, C., Goodess, C. M. \& Jones, P. D. (2012). Simulating climate change in UK cities using a regional climate model, HadRM3. International Journal of Climatology, 32, 1875-1888

10 Dobney, K., Baker, C. J., Quinn, A. D. \& Chapman, L. (2009). Quantifying the effects of high summer temperatures due to climate change on buckling and rail related delays in south-east United Kingdom. Meteorological Applications, 16, 245-251.

11 Dobney, K., Baker, C. J., Chapman, L. \& Quinn, A. D. (2010). The future cost to the United Kingdom's railway network of heat-related 
occur when maximum temperature exceeds $27^{\circ} \mathrm{C}$, based on an analysis of the occurrence of rail buckling events reported in the Network Rail Alteration database and the corresponding observed temperature. Thus, a threshold of $27^{\circ} \mathrm{C}$ has been defined for initial analysis of UWG outputs. The first step of this analysis is to identify the frequency with which this threshold will be exceeded for a given climate scenario and future time period, and thus to provide hazard maps reflecting the spatial extent and severity of heat events. Analysis of UWG outputs for each climate scenario was undertaken on multiple runs with various climate model change factors for the same location, timeperiod, and emission scenario. Figure 1 shows the probability of the annual number of days where the maximum temperature in one or more grid cell in the study area exceeds the $27^{\circ} \mathrm{C}$ threshold for a range of time-periods and climate scenarios.

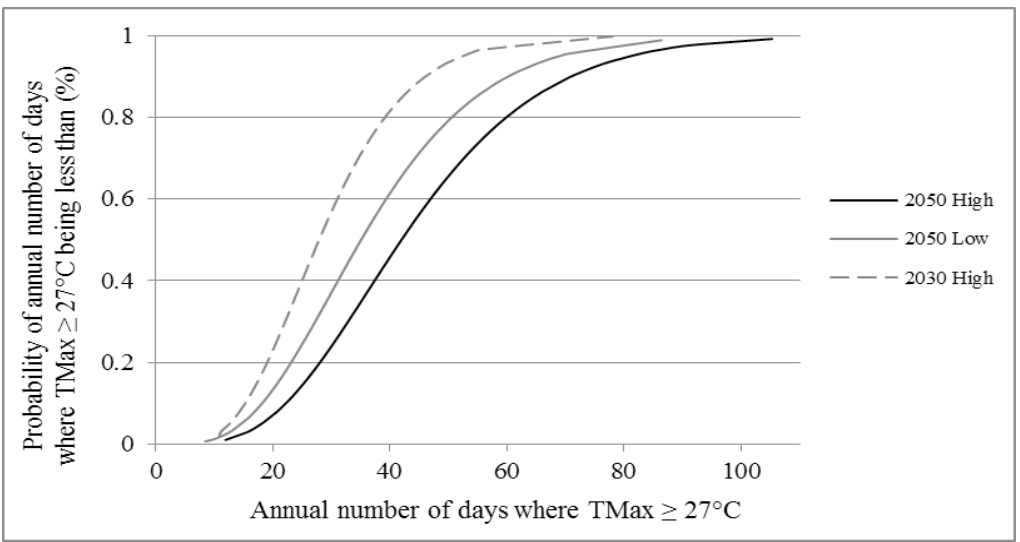

Figure 1: Probability of the annual number of days where TMax exceeds $27^{\circ} \mathrm{C}$ for one or more grid cells in the study area, for the 2030s and 2050s under low and high emission scenarios

To analyse the impact of these events on the users of the transport network, further temperature thresholds are related to speed restrictions imposed on sections of railway line (see Table 1). Single days in the UWG outputs are identified at least one grid cell exceeds one of these thresholds and then the maximum daily temperatures for each of these events can be mapped spatially across the study area on the $5 \mathrm{~km}$ grid (Note: these are air temperatures, but methods are being developed to examine surface temperatures, which are of more relevance for impacts on railway infrastructure). Figure 2 shows the number of times each grid cell in the London study area exceeds the $27^{\circ} \mathrm{C}$ temperature threshold.

\begin{tabular}{|l|l|}
\hline Threshold & Speed restriction \\
\hline$<27^{\circ} \mathrm{C}$ & None \\
\hline Poor Rail Track $\geq 27^{\circ} \mathrm{C}<28^{\circ} \mathrm{C}$ & $30 \mathrm{mph}$ \\
\hline Poor Rail Track $\geq 28^{\circ} \mathrm{C}$ & $20 \mathrm{mph}$ \\
\hline Moderate Rail Track $\geq 33^{\circ} \mathrm{C}<35^{\circ} \mathrm{C}$ & $60 \mathrm{mph}$ \\
\hline Moderate Rail Track $\geq 35^{\circ} \mathrm{C}$ & $20 \mathrm{mph}$ \\
\hline Good Rail Track $\geq 36^{\circ} \mathrm{C}$ & $90 \mathrm{mph}$ \\
\hline Good Rail Track $\geq 42.6^{\circ} \mathrm{C}$ & $60 \mathrm{mph}$ \\
\hline
\end{tabular}

Table 1: Temperature thresholds where speed restrictions are imposed. Source: Network Rail (2008) 


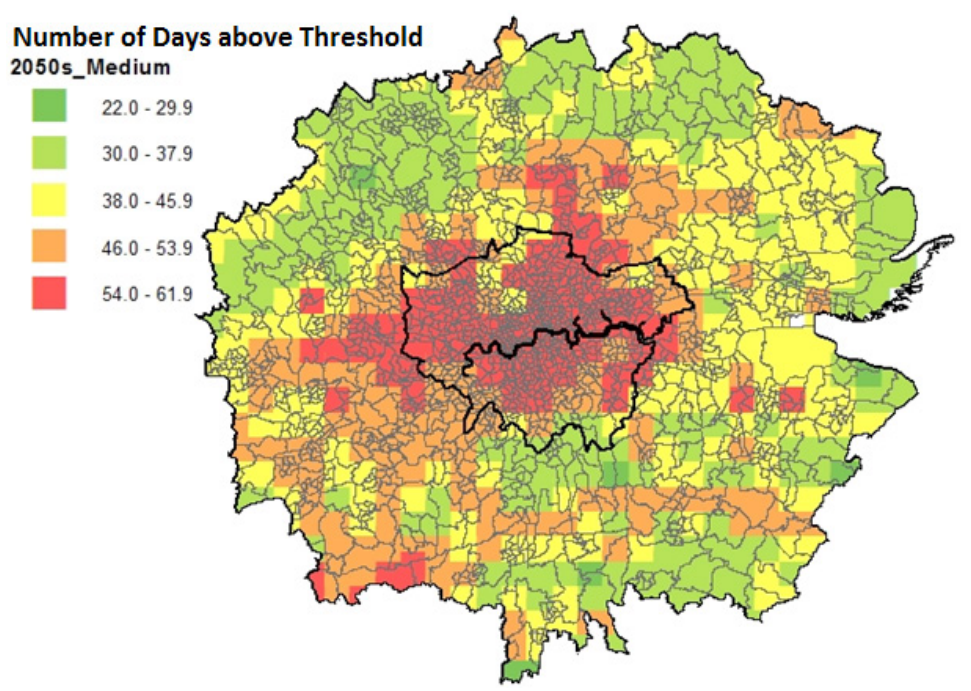

Figure 2: Number of days in a given 100-year simulation from the UWG for Greater London where the maximum daily temperature exceeds the $27^{\circ} \mathrm{C}$ threshold.

\section{FLOODING IMPACTS}

Pluvial flooding, where intense rainfall overwhelms urban drainage systems, is sensitive to the spatio-temporal characteristics of rainfall, topography of the terrain and surface flow processes influenced by buildings and other man-made features (Glenis et al, 2013)4. Urban flood models can provide outputs of surface water depth and velocity at very high resolution, with surface water flow being modelled using two-dimensional hydrodynamic equations (ibid). Impacts on the transport network due to flooding can be analysed by examining the coincidence of these outputs with the spatial locations of urban transport infrastructure. The CityCat simulations are also driven by UKCP09 outputs, giving future estimates of rainfall across the study area. In this study, however, a particular event derived from the Flood Estimation Handbook (2 hours of duration, 200 ys return period) was analysed, producing a flood hazard map at $1 \mathrm{~m}$ resolution depicting the resultant depths and velocities of surface water. An example output is shown in Figure 3.

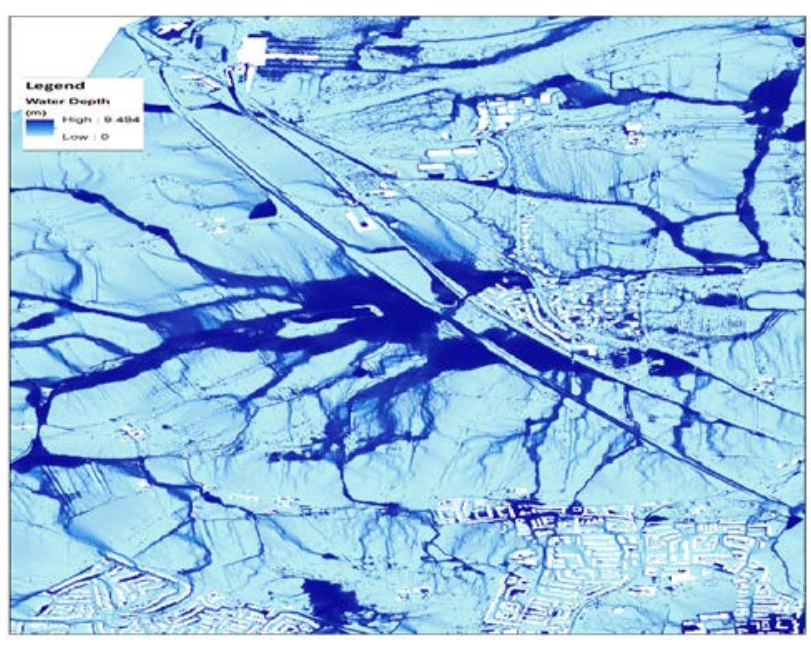

Figure 3: an example output from CityCat showing the depth of water across an urban area during an extreme rainfall event.

For calculation of flooding disruption on transport networks a threshold is again defined, above which it is expected impacts from surface water floods will be felt. In this paper, disruption to road networks is presented. Expert guidance (e.g. Green Flag, 2014) ${ }^{12}$ states that a water depth of $0.25 \mathrm{~m}$ is the point at which driving becomes unsafe, but due

12 Green Flag, (2014). Driving in floods and heavy rain (advice). http://www.greenflag.com/advice/driving/floods.html - retrieved 6th June, 2014 
to the uncertainties in this value (e.g. type of car, type of asphalt, type of tyre, behaviour of the driver, visibility) a more conservative depth of $0.2 \mathrm{~m}$ was defined as the threshold where speed will be reduced. A speed of $6 \mathrm{~km} / \mathrm{h}$ was defined as the speed at which cars can pass through water above this depth.

\section{NETWORK MODELLING}

Whilst the climate hazards described above will obviously have wide-ranging impacts on the transport infrastructure itself, causing direct damages (e.g. through rail buckling due to extreme heat), the focus of this study is on the impacts on the users of those networks in terms of disruption to their journeys. Thus, a simple model of network trips was developed to gain an understanding of both the relative importance of network segments (in terms of their levels of use) and the number of people affected by a disruption to the network. This model used the simple Frank-Wolfe algorithm (Dafermos, 1968) ${ }^{13}$ to load journey-to-work (JTW) observations from the 2001 UK census onto network models in GIS.

Two network representations were constructed in this study from a variety of data sources (e.g. Ordnance Survey ITN and Meridian data, UK NAPTAN data for public transport stops), one for private (e.g. road) transport and one for public transport. These networks were supplemented with speed and capacity information to allow the calculation of shortest routes in terms of time. These shortest routes were thus computed between origin and destination locations for the JTW observations and the observed flows assigned to the segments of the network included in these shortest routes. In this way, it is possible to build up an estimation of the number of people using links in the urban transport networks as part of their daily commute.

\section{SPATIAL ANALYSIS OF IMPACTS}

Once spatial footprints of hazards, either from heat or flooding, have been defined they can be overlaid on spatial representations of the urban transportation networks in GIS to allow the calculation of disruption. The method for undertaking this calculation is the same for both heat and flooding impacts since a threshold approach has been applied for both. Thus, the process involves overlaying the spatial footprint of the hazard (i.e. a $5 \mathrm{~km}$ grid cell in which the defined temperature threshold has been exceeded, or a $1 \mathrm{~m}$ grid cell in which surface water depth has exceeded the defined flood threshold) onto the transport network and determining the portions of the transport network affected. The travel speeds on the disrupted network segments are then adjusted and new travel times between sets of origins and destinations calculated. By comparing the perturbed travel times with the original travel times before disruption, the impact on commuting journeys can be measured, and since the number of journeys using that route is known from the JTW table, the total impact in terms of Person-Minutes can be computed.

\section{RESULTS}

For heat disruption, 18 daily events in Greater London were produced by sampling across a range of event magnitudes sampled from $30 \times 100$ year weather generator simulations. The magnitude is defined as the product of the number of grid cells in the study area above the $27^{\circ} \mathrm{C}$ threshold and the amount by which the threshold is exceeded. For each of these events, a map of daily maximum temperature was produced and overlaid on the railway network as described above. Depending on the simulated temperature and its location, the impact on the railway network can be calculated in terms of speed restrictions and thus increased travel times.

Figure 4 shows the relationship between the magnitude of each sampled event and the total person delay in minutes which results from the disruption to the network. It can be seen that the extent of the disruption to the network very quickly reaches saturation and that there is some variation in the disruption depending on where in the network

13 Dafermos, S. and Sparrow, F. (1968). The Traffic Assignment Problem for a General Network. Journal of Research of the National Bureau of Standards, 73B, pp. 91-118. 
the hottest areas occur. In this example, it is assumed that all track in the simulation is of Poor quality (see Table 1). In order to represent simple adaptation to future temperature changes, similar simulations were also run with assumptions that all track was Moderate or Good.

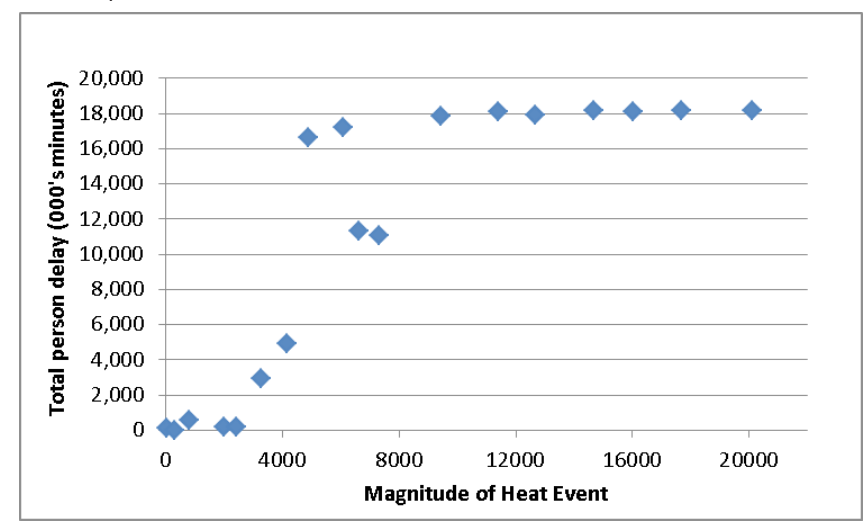

\section{Figure 4: Total delays for each of the 18 events of different magnitudes}

For flooding impacts, disruption to the road network in the Tyne and Wear area of the UK was simulated as described above. Figure 5 shows the impact of a single flooding event ( 2 hours of duration, 1 in 200 years return period) in terms of delays to car journeys using the simple thresholding approach. It can be seen that the modelling flooding area is relatively small (due to the computational overheads of the CityCat model) but that the resultant disruption is wide-ranging. The resulting disruption is in terms of time delays for each origin-destination pair.

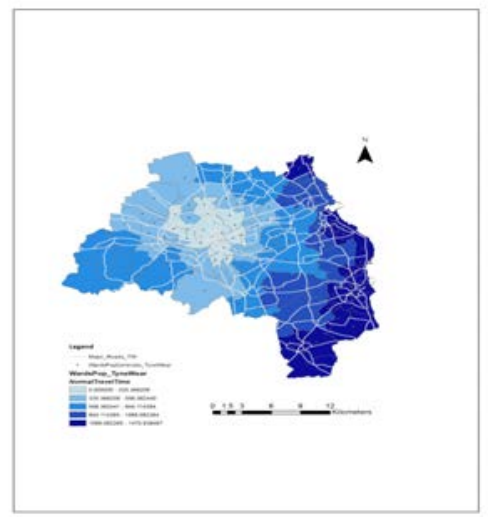

Pre-event travel time (minutes)

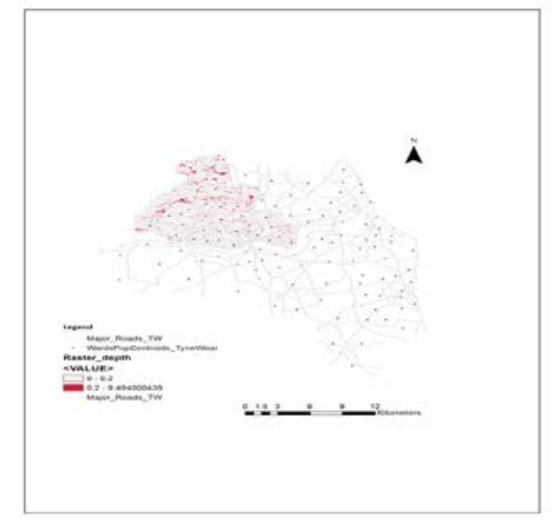

Areas (in red) where flood depth from CityCat model exceeds $0.2 \mathrm{~m}$

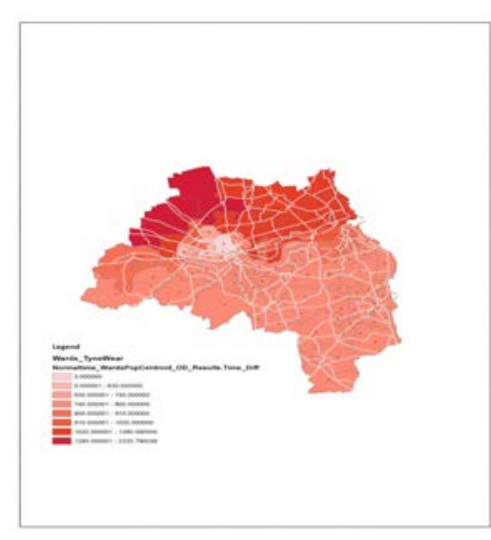

Resultant delay (seconds) to road commuter journeys

Figure 5: Modelling of disruption to urban road network from flooding

\section{CONCLUSION}

This paper has presented an approach to examine the impacts of extreme weather events on urban transport infrastructure by combining climate simulations with spatial representations of networks. It has been demonstrated that a thresholding approach allows spatial hazard footprints to be extracted and overlaid onto network models in GIS to produce measures of disruption to commuting journeys on road and public transport networks. Whilst only current day population, from census JTW tables, has been examined in this paper, this approach can also be applied to future populations using land-use transport interaction models, allowing the examination the impacts of future socio-economic changes alongside changes to the climate.

\section{ACKNOWLEDGEMENTS}

Part of the research in this paper was funded by the UK Engineering and Physical Sciences Research Council grant EP/G061254/2 to the ARCADIA project, for which the authors would like to express their appreciation. 